one afternoon, in a hurry, to see her. On arrival, I saw again, to my intense chagrin, the spectral ghastly grin, maniacal rolling eye, and the furtive glance so well remembered; and though, as yet, the shouting demeanour was absent, there was the whispered entreaty for morphia, which she had not used for more than eighteen months. As if this were not discouragement enough, I discovered, upon vaginal examination, that the stem pessary which she continued to wear was not this time out of order. It was in perfect apposition, and erect in attitude. Independent of the treatment by pessary, nothing but morphia had been found able to moderate the violence of these outbreaks; and the employment of morphia I had rigidly forbidden on account of its pernicious effects on her constitution, moral and physical. The day was far advanced and night coming on, with the prospect of the household being turned into a veritable pandemonium. On casting about for some cause for this unpleasant return of her tormentor, I learned that the menses had been rather suddenly stopped by a chill. The left inguinal region was tender to the touch, whilst the left ovary, per vaginam, was felt to be swollen, and the slightest pressure over it was acutely painful to the sufferer. Here, therefore, appeared to me sufficient cause for the nervine disturbance. At least, careful inquiry could suggest no other. Whilst standing by the bedside, watching the vagaries of the patient, in a thoroughly crestfallen mood, the idea of digitalis suddenly struck me. How it was known to stimulate Setschenow's inlibitory ganglia at the upper part of the spinal cord, and, further, its sometimes happy effect when boldly administered in delirium tremens, recurred to $\mathrm{my}$ mind. The patient's pulse, too, was at all times high and feeble; but during hysterical paroxysms was even alarmingly so. Digitalis, therefore, being a powerful cardiac and vascular stimulant, seemed very appropriate. The result is soon told. I prescribed half an ounce of the tincture in a fourounce bottle, with water; two tablespoonfuls (one-drachm dose of the tincture of digitalis) to be taken every hour. This was at five o'clock, and I did not see her again till between nine and ten o'clock. She was then quite calm and reasonable; a perfect contrast to her previous state. The four doses had all been taken. Previously the pulse had ranged from 120 to 130 , and was very feeble in character, even at times difficult to detect. Now, on the other hand, it was steady and full, beating rather over 90 to the minute. On other occasions morphia alone had been able to break through the persistent sleep vigil; on this, however, the patient declared she felt drowsy and thought she could go to sleep. This result was happily realised, and an excellent night passed. Next morning she awoke refreshed, got up, and said she was quite well. Better still, she has remained so to the present date.

I would remark, in conclusion, that this case seems to teach a useful lesson regarding the value of digitalis employed as an alternative to agents such as hydrate of chloral, bromide of potassium, nitrite of amyl, Calabar bean, and others so generally used as controllers of disturbed reflexes. These otherwise useful agents tend unfortunately to weaken the heart's action and lower the circulation generally. In poisonous doses they arrest the heart in diastole, whereas digitalis, similarly administered, stops the heart in systole. Digitalis also slows the cardiac beat, whilst it increases the force and efficiency of the contractions. In suitable cases, then, we would do well to remember that these most useful therapeutic powers of digitalis are united to others equally potent and valuable, which give control over reflex nervine disturbances. The result of careful experiments appears toestablish that this influence over the reflex centres, as well as over the spinal cord generally, is really independent of the characteristic effects upon the heart and the bloodvessels. The latter potentiality, however, may not improbably assist the former; consequently, where long courses of the bromides and other depresso-motors are found necessary, a combination with digitalis is suggested, to avoid any weakening of the circulation liable to be produced by the former agents. In this direction the character of the pulse will be found a proper guide, for, when full and strong, digitalis will not be needed; but, when feeble and frequent, such assistance would be evidently indicated. There are, on the other hand, occasional instances where medicines commonly relied on and found most useful as sedatives to spinal irritation, have failed; and in such, as in the case I have related, digitalis may happily prove invaluable as the last arrow in the quiver of the long-suffering medical attendant.

\section{A NOTE AND A. QUESTION ON SO-CALLED SURGICAL SCARLET FEVER.}

By HERBERT W. PAGE, M.A.CAntab., F.R.C.S., SURGEON TO ST. MARY'S HOSPITAL.

"Ought an operation to be performed on a patient whom we know to have been recently exposed to the contagium of scarlet fever?" is a question which cannot very often have presented itself to a surgeon; but it occurred to myself not long ago in the following circumstances.

On Dec. 13th, 1884, I admitted into St. Mary's Hospital a patient with suppurating glands and old sinuses in the right groin, the result of over-exertion, and perhaps general ill-health. On Dec. 13th the sinuses were freely laid open under an anæsthetic, the operation being a somewhat severe one of its kind. On the 18th the temperature rose, and a red rash appeared on the chest and abdomen. This was followed by sore-throat and general extension of the redness, and no doubt was entertained that the patient had scarlet fever. He passed through a mild course of this disease and desquamated over the whole body; but there was little or no arrest in the healing of his wound, and he was discharged from the hospital in eight weeks. He was an intelligent well-educated man, aged twenty-eight, formerly an officer in the Navy, and had been taken into the hospital for special reasons. He was quite unaware of having been exposed to recent contagion, but was sure that he had had scarlet fever twice before, the last time seven years ago.

There attended on this patient a night-nurse and a daynurse, both lady probationers in the hospital. On Dec. 27 th the night-nurse, aged thirty-five, began with scarlet fever, and passed through a typical yet very mild attack. On Jan. 7th the day-nurse, E. P. G-, aged forty-seven, called attention to the fact that her left breast had been for some time very painful and was growing rapidly in size. I was asked to see her, and learned that for the last fifteen years she had had a small painless lump in the breast, that it had begun to increase in size nine months ago, and that for the last two months its growth had been much more rapid, with a considerable amount of pain. The breast was found enormously enlarged, and to be the seat of a tumour which, both from the history and the feel, was obviously a cystic adeno-sarcoma. I advised removal as soon as possible-that, at any rate, it should not be delayed beyond a week or ten days. On the following day her friends took her to see Sir James Paget, who further advised that she should leave the hospital for a few days before operation, so as to lessen the risks of her contracting scarlet fever, to infection from which she had been continuously exposed for the last three weeks. She had never had scarlet fever before. Accordingly, she left the hospital at once, and returned on the morning of Jan. 14th, on which day I had the advantage of talking over the case with Sir James Paget, who agreed in thinking that it was right, in the circumstances of the breast disease, to operate, although the chances of the patient developing scarlet fever were very considerable. On the afternoon of Jan. 14th I removed the breast under full antiseptic precautions, Listerian carbolic spray and gauze. The wound healed by first intention; and from that moment to her discharge from the hospital, on Feb. 9th, her temperature never rose above the normal. She did not contract scarlet fever.

Such is the bare statement of the facts, and it will be acknowledged, I think, that a question of unusual difficulty was submitted to the surgeon before operation. The fortunate issue of the case gives at any rate one answer to the question, that an operation may be performed with safety on a patient who has been recently exposed to the contagium of scarlet fever. Operations have doubtless been frequently performed without ill results on persons who have been so subjected to infection, although that fact was unknown both to themselves and the operators. I question, however, if an operation other than one of real urgency ought to be undertaken knowingly in like circumstances, and I must own that for some days after the operation on E. P. G- my anxiety was not small that she would show evidences of the fever. The necessity and urgency of the operation had to be weighed against the risks of developing scarlet fever, and had any facts been at hand to tell that the patient would certainly show symptoms of this fever after operation, that there was, in fact, no possible escape for her from such a U 2 
consequence, then perhaps it would have been right to postpone the operation longer, urgent though it was. But who could say for how long? There were no such facts to guide me, and I thought it justifiable to take the chance and do the operation.

The history of these three patients clearly shows how different is the susceptibility of different individuals to the poison of scarlet fever. The man who had had scarlet fever twice before gets a third attack within four days of an operation; from him one nurse soon catches the disease, and the other nurse, who was subjected to no less risks of infection and who had not had scarlet fever before, not only does not acquire it, but even undergoes a serious operation within a week of the time when she had been nursing him. It appears, therefore, that an operation, or the state of depression induced thereby, has not that power which has been attributed to it of permitting the development of scarlet fever in a patient who has been exposed to it, unless the patient has also a certain measure of susceptibility to the disease. Nor do I know how this is to be gauged, unless it be from the age of the patient and the absence of any previous history of scarlet fever. It is improbable that anyone can havereached middle life without having been at some time exposed to the risks of infection, and in the system of every individual there must be something to determine whether poison or system shall prevail, whether the poison which has entered in shall run its course, or be deprived of its potency and cause no symptoms. That different persons and different families show all degrees of susceptibility is of course well known, and the history of these three cases seems to point to individual susceptibility as having an all-important share in allowing the development of scarlet fever after operation. How widely different, for example, must have been the susceptibility in the man and in his nurse. This conclusion seems, however, to teach that an operation ought not to be undertaken in such circumstances as have been recorded unless there be some good reason for believing that the patient's susceptibility is only small. The question which begins this paper can, as has been said, very rarely present itself to a surgeon, and I can only suggest that when it occurs very careful inquiry should be made into the history of the patient and his family, that his age be noted, and the probabilities of his exposure to contagion, and his escape from its dangers during his previous life, be fully considered. And yet his previous escape may render him more liable to an attack now, and an operation may be the one thing needful to make him fall a victim to the fever. Not necessarily so, as the case in this paper shows; but there must be a risk, and it should be fairly put before the patient and his friends. Risk unaroidable; attack by no means inevitable; hope of escape well-grounded or the reverse, according to the age and previous history. These are the considerations which must be put before them, and which must be balanced against the measure of the urgency for the operation. How difficult it may be to arrive at a right conclusion is self-evident.

In a letter to me on the issue of this case Sir James Paget writes: "I wish we could have more of these negative facts; we have nothing to weigh against the positive evidences of the bringing out of previous infection." It is with the object of recording a negative fact of much interest and importance that I venture to publish this note.

\section{NOTES ON}

\section{A CASE OF ABDOMINAL SECTION.}

\section{By C. A. BRODRIBB, M.R.C.S.}

Mrs. F-_-, aged forty-one, a widow with six children, was about her household work, in her usual health, on May 24th, 1881. The next day she was seized with severe pain in the abdomen, with constant vomiting. The pain seemed most severe in the right lumbar region, over the ascending colon. She said she felt that "something had given way in her inside." I was sent for in the evening of the next day (the 26th). I found her in great pain, frequently retching; pulse 108, weak; skin moist and cool. I ordered her to take fifteen minims of tincture of opium in an ounce of chloroform water every four hours, to suck ice, and to apply warm flannels over the abdomen. The next day (27th) she was much the same, but an indistinctly defined swelling over the ascending colon had appeared, extremely tender to the touch. On the 28th I asked Dr. Bagshawe to see her with me. The swelling was more defined, pain intense, but very little vomiting. Pulse 108 ; temperature $99.5^{\circ}$. No motion and no flatus had passed since the illness began. Ordered half a pint of warm oil with a quart of warm water, as an enema; twenty minims of tincture of belladonna every four hours; extract of belladonna to be applied over the tender swelling, which now had a sharply defined edge below, ending upwards indistinctly. The enema washed cut a little freces and flatus. Dr. Bagshawe thought that the ascending colon had become strangulated by adhesive bands of lymph. So matters continued for the next two days; no motion or flatus passed, and the swelling became more distinct and more tender. On May 31st the case was obviously almost hopeless if left to itself, and it was plainly unwise to wait until the patient became feverish or collapsed. Mr. Travers also kindly saw the case on the 31st with Dr. Bagshawe and myself, and we all agreed that the only chance lay in abdominal section, with a riew to release the strangulated bowel. Accordingly, that afternoon, Mr. Travers chloroformed the patient, and having rinsed my hands and the sponges in a little carbolic acid and water, I made an incision in the median line, about five inches long, from just below the umbilicus downwards. I carefully stopped all the little bleeding vessels by torsion before I opened the peritoneum, which I did, of course, upon a director. I then introduced my hand, and passing it on to the ascending colon, I found it surrounded by adhesions of recent lymph, which I easily broke down with my forefinger. I also found a distinct band of lymph transversely across the bowel, and I managed to get my finger under it and broke it. I then drew the bowel sufficiently towards the incision to be able to get a glimpse of it. It was deeply congested, but sound. I afterwards squeezed onwards the contents of the swollen gut, especially one or two hard scybala, and left it soft and gurgling. I found some little difficulty in preventing the bowels from protruding en masse through the incision, but with a little more care $I$ was able to close it securely with two deep silver-wire sutures through the peritoneum and four superficial sutures of silk. I dressed the wound with a little piece of lint soaked in carbolised oil, and then put over it a good-sized pad of wadding, with strapping, and six yards of wide calico bandage. I then gave half a grain of morphia under the skin, and ordered nothing but ice by the mouth. The same night the patient passed flatus per anum, but towards morning she had frequent and copious stercoraceous vomiting; temperature $97^{\circ}$; pulse weak. I gave drachm doses of brandy every two hours, and she rallied, and took a little of Brand's essence of beef. For the next two days she continued to improve, and passed flatus freely lost all pain and swelling in abdomen. On June 3rd sh had a large enema, which gave copious relief; wound healthy and healing well. On the 4 th she had a relapse, with pain in the epigastrium and temperature $102^{\circ}$, which I attributed to a small slice of roll injudiciously given by a visitor. However, this attack subsided, and on the 5th (six days after the operation) the bowels acted freely of their own accord, the temperature fell to normal, and the pulse improved. On the 6th I removed the sutures, as they caused a "pricking" pain, and I found the wound all healed by first intention. I continued of course to support it with strapping and bandage. I gradually improved the diet, and on the 7 th the patient sat up. She is now (seventeen days after the operation) weak, but able to go downstairs, and is practically quite well.

The points of interest to be noted in this case are: first, the rarity of the operation itself in private practice, as it is generally only resorted to as a forlorn hope; secondly, the favourable result, without any special advantages, such as hospital treatment and nursing and antiseptic precautions. The cottage in which the patient lives is one of a row of little houses in a crowded part of the town not particularly clean, airy, or well drained. The operation itself presents no particular difficulty, and requires no great skill in the operator and this case seems to show that the dangers of abdominal section have hitherto been somewhat over-estimated; and that elaborate antiseptic treatment (which cannot well be obtained at the homes of the poor) is not necessary. Cases of intestinal obstruction are sadly common in the practice of all medical men, and are almost always fatal. I venture to hope that my professional brethren may be encouraged by this case to endeavour to save life in such cases by operation when other means seem likely to prove of no arail. 